\title{
Epidural blood patching under fluoroscopic guidance for the treatment of post dural puncture headache versus conventional method
}

\author{
Dr. Katary A, Elsaudi E, Ahmed O, Elkhateeb S
}

\section{BACKGROUND and Goal of Study:}

Epidural analgesia is considered the gold standard for labour analgesia. However, accidental dural puncture is not uncommon and more cases of accidental dural puncture are being seen. Postdural puncture headache is a serious and bothersome complication of accidental dural puncture; being more common in females and in middle age group. Together with the large gauge of epidural needle, we are faced with a higher risk of dural puncture in labouring women and also a higher chance for the postdural puncture headache to develop. Epidural blood patch is the main stay for the treatment of postdural puncture headache when conservative treatment fails.

\section{Materials and Methods:}

This study was carried as a PhD thesis in AlAzhar university, Egypt on 60 women who suffered postdural puncture headache after accidental dural puncture during epidural labor analgesia, between January 2012 and December 2013. Epidural blood patch was performed after failure of conservative treatment for 24 or 48 hours depending on the severity of headache. Patients were randomly allocated into two groups; 30 patients each.

Group I: Epidural blood patch was done under fluoroscopic guidance, until covering the suspected site(s) of dural puncture plus a space above and a space below.

Group II: Epidural blood patch was done under no image guidance, administering $20 \mathrm{ml}$ of blood or less if limited by back pain.
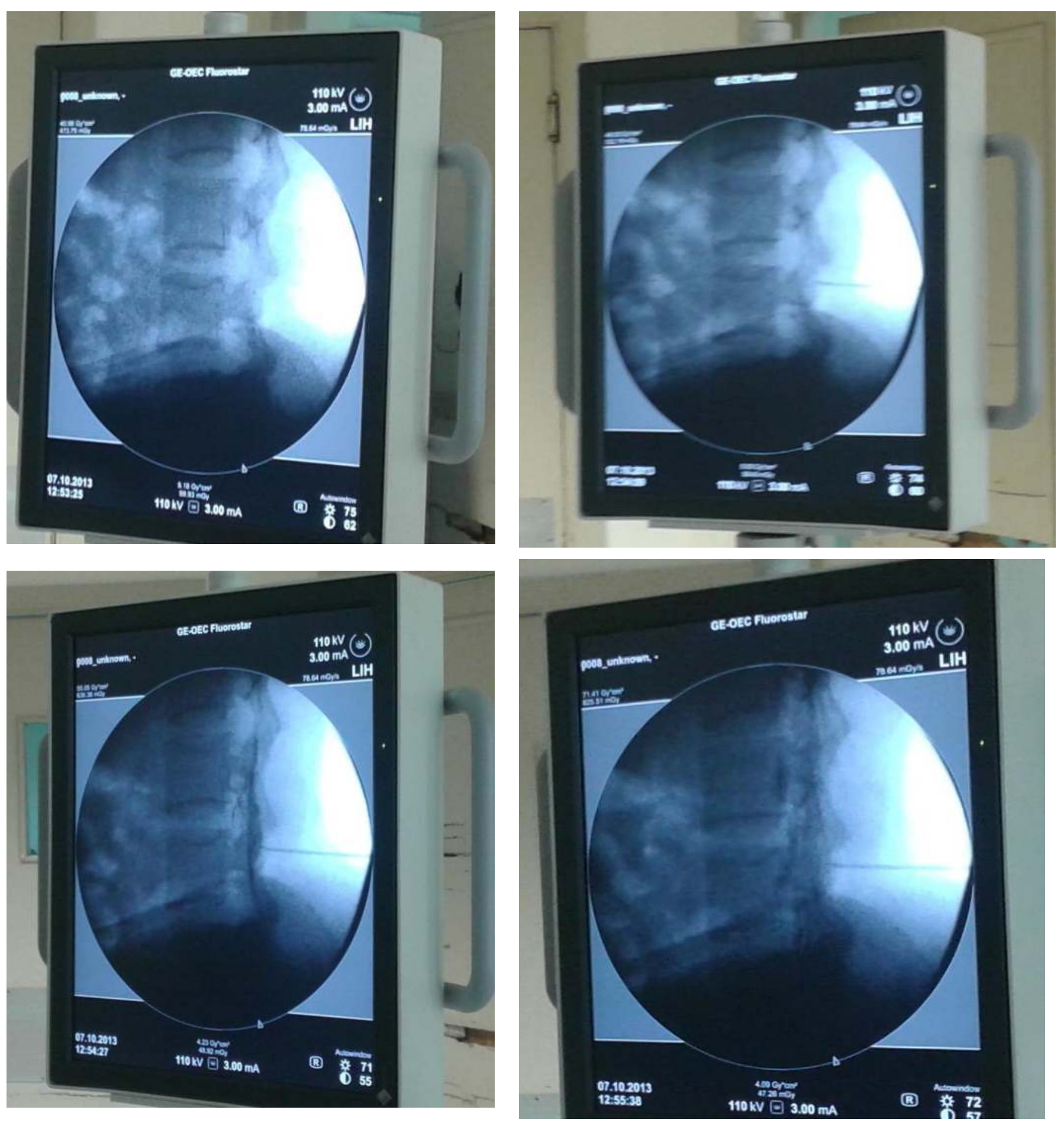

Results and Discussion:

All of the following were significantly lower in the fluoroscopy group; the mean volume of the blood patch $(10.6 \mathrm{ml}$ vs. $16 \mathrm{ml})$, headache scores at 2,6 , 12 and 24 hours, the number of rescue analgesics needed during the first 24 hours following the blood patch, the VAS of back pain after 2 hours of the blood patch and the number of attempts to reach the epidural space. Regarding the number of patients who required a second epidural blood patch, though the difference was not statistically significant, but still fewer patients in the fluoroscopy group required a second blood patch compared to the control group ( 5 and 9 respectively)
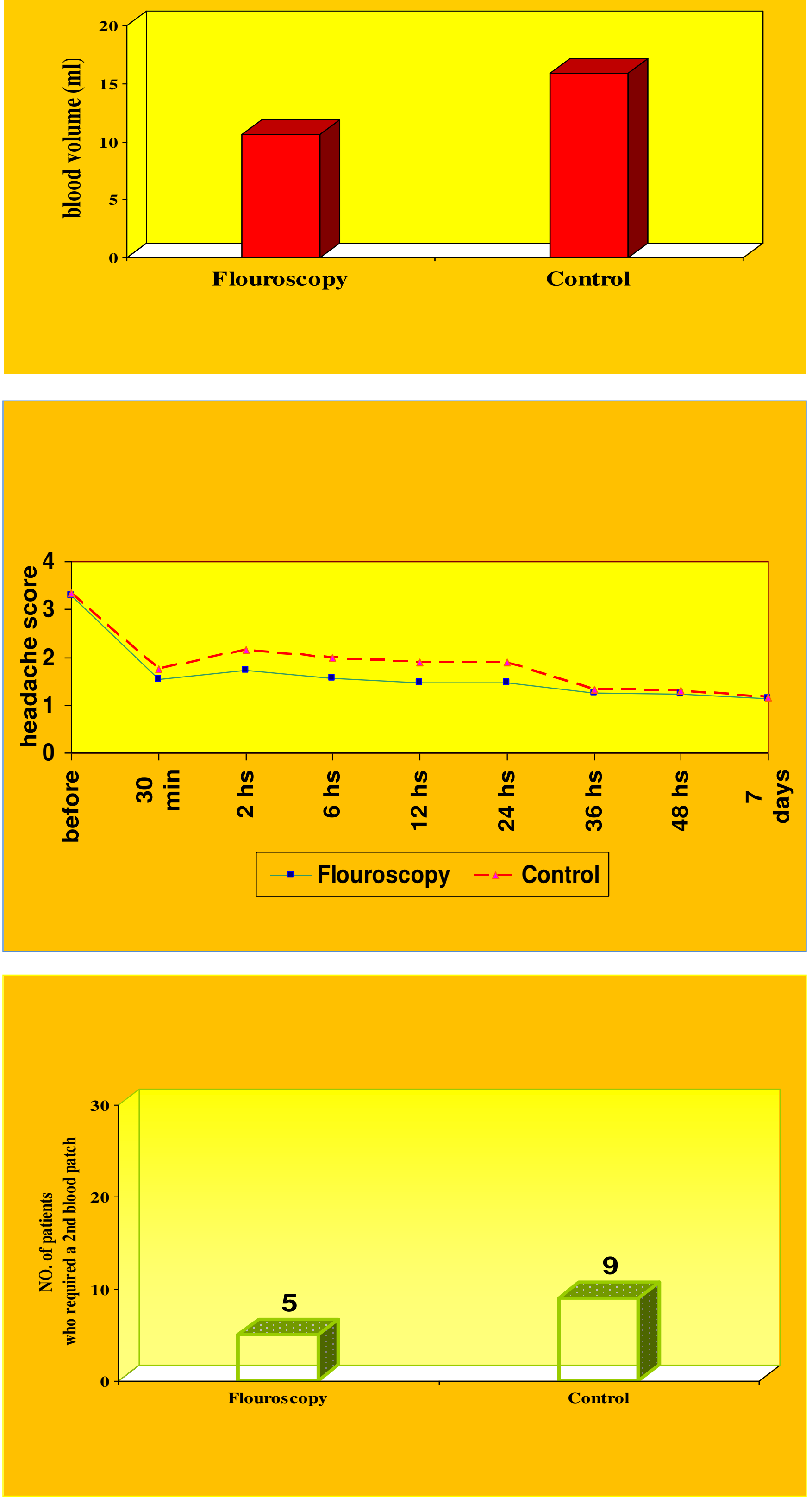

CONCLUSIONS:

Performing epidural blood patch under fluoroscopic guidance increases its success rates and decreases the headache scores significantly and decreases the incidence of back pain and complications and helps determine the exact volume of blood to be injected on individual basis.

\section{RECOMMENDATIONS:}

1. The administration of EBP for the treatment of PDPH when conservative modalities fail.

2. We also recommend the routine performance, unless contraindicated, of EBP under fluoroscopic guidance. 